Original Research Article

\title{
Assessment of drug attitude, medication adherence and quality of life among psychiatric patients in South Indian population: a cross sectional study
}

\author{
Suganya Ganesan, Nitya Selvaraj*, Vinoth Krishna Dass, Nalinidevi Jayabalan, \\ Meher Ali Rajamohammad, Isswariya Anandan
}

Department of Pharmacology,

Sri Manakula Vinayagar

Medical College and Hospital,

Puducherry University,

Puducherry, India

Received: 26 September 2018

Revised: 28 October 2018

Accepted: 01 November 2018

*Correspondence to:

Dr. Nitya Selvaraj,

Email: sugalss@gmail.com

Copyright: (C) the author(s), publisher and licensee Medip Academy. This is an openaccess article distributed under the terms of the Creative Commons Attribution NonCommercial License, which permits unrestricted noncommercial use, distribution, and reproduction in any medium, provided the original work is properly cited.

\begin{abstract}
Background: In spite of many progresses in treatment of psychiatric disorders, medication nonadherence plays an important role in worsening of clinical condition and affects quality of life among psychiatric patients. There are numerous factors contributing for medication nonadherence among patients with mental illness. So, this study was conducted to assess psychiatric patients' adherence of medication and to improve their quality of life with psychiatric disorder. The objectives of the study were to analyze impact of pharmacophilia and pharmacophobia on medication adherence among patients with psychiatric disorders at a tertiary care hospital and to assess quality of life among pharmacophilic and pharmacophobic patients.

Methods: A cross-sectional study was conducted in outpatient psychiatric department for a period of two months. After obtaining informed voluntary consent, patient's socio-demographic details, diagnosis, and treatment were recorded from prescription slip. Patients above $18 \mathrm{yr}$ age with psychiatric diagnosis as per International Classification of Diseases 10 (ICD-10) and receiving at least one psychotropic medication for $>1$ month were enrolled in study and assessed using: Drug attitude inventory classification (DAI-10); Medication Rating Scale (MARS); Quality of life enjoyment and satisfaction Questionnaire-Short Form (Q-LES-Q-SF).

Results: Among 130 patients, 116 were pharmacophilic and 14 were pharmacophobic as per DAI-10 scale. $81.9 \%$ of pharmacophilic were adherent to prescribed medication assessed using MARS scale only $14.3 \%$ were pharmacophobic. The quality of life was better in pharmacophilic compared to pharmacophobic group ( $\mathrm{p}=0.002)$ using Q-LES-Q-SF.

Conclusions: This study concluded that pharmacophilic patients have higher adherence and good quality of life index compared to pharmacophobic. Proper counselling of pharmacophobic patients by psychiatrists could improve adherence and QOL.
\end{abstract}

Keywords: Medication adherence, Pharmacophilic, Quality of life

\section{INTRODUCTION}

Global burden of psychiatric disorders among population showed that 450 million people were affected. ${ }^{1}$ Various survey shows that USA has the highest rate of psychiatric illness of $26.4 \%$ followed by other countries. ${ }^{2}$ About $20 \%$ of the adult population are affected by psychiatric disorders in India, which requires intervention from mental healthcare professionals. It is estimated that among many diseases mental and behavioral disorders are more common with a statistical significance. ${ }^{3}$ Several new atypical antipsychotics and antidepressants are used in treatment of both negative and cognitive symptoms. ${ }^{4}$ However accurate diagnosis and treatment are essential for 
better outcome and to provide good quality of life. ${ }^{5}$ Drug attitude of psychiatric patients was mediated by health locus control, self- efficacy and cognitive psychological reactance. "Pharmacophobic" which is the expression of the negative attitude towards medication and "pharmacophilic" which is the expression of the positive attitude is of great interest for medication. These two aspects are concerned with the use of psychotropic drugs among patients. ${ }^{6}$ The success of the treatment mainly depends on the patient's knowledge about the outcome of disease control. ${ }^{6}$ The recent study showed that there is a connection between adherence to treatment and belief of patient about intake of the drugs. ${ }^{7}$

Adherence denotes patients understanding and acceptance about the positive and negative effects of drugs prescribed to them. ${ }^{8}$ Adherence to prescribed medication usually correlated to good health outcome. ${ }^{9}$ According to WHO, adherence to treatment for chronic illness in developed countries averages $50 \%$ and lower in developing countries. $^{10}$ So, the nonadherence or failure to take medication in patients remains a barrier for effective management and it remains a major challenge in current psychiatric clinical practice and leads to increased risk of recurrence, relapse, and mortality. ${ }^{11,12}$

Nonadherence may also lead to poor quality of health and also affects daily routine of patients with psychiatric illness. Quality of life (QOL) is a multidirectional, constructed on social well-being and life satisfaction of life. ${ }^{13}$ The patients with affective disorders found to have significant QOL impairment, till now only limited studies are available on patient's attitude and adherence about the psychiatric treatment and there were no previous studies done in assessing the QOL among pharmacophilic and pharmacophobic group of patients. ${ }^{13,14}$ Hence, this study was designed to analyse the impact of pharmacophilia and pharmacophobia among patients with different psychiatric disorders and their adherence to the therapy of medication and QOL, at a tertiary care hospital.

\section{METHODS}

It is a cross-sectional study. Information of the patient's socio-demographic details, health, living status, diagnosis and treatment given were recorded from the prescriptions given by the consulting doctors and questionnaire were given to the patients, using data collection form in their regional language. If the patient is uneducated or unable to understand the questions, then it was explained by the investigator. Initially, patients were assessed whether they were pharmacophilic or pharmacophobic followed by the assessment of quality of life using standard questionnaire model. The informed written consent was obtained from all study subjects. Throughout the study confidentiality of patients' details were maintained.

Institutional Human Ethics Committee's approval (Code No: 49/2017) was obtained and the study was conducted according to "Good clinical practice" guidelines. The study was conducted in the Department of Psychiatry for 2 months. The Sample size was calculated using $4 \mathrm{pq} / \mathrm{d}^{2}$ formulae, Where $\mathrm{P}$ is the proportion of psychiatric people who are nonadherent to treatment $(43 \%$ as mentioned in the previous study). ${ }^{8} \mathrm{q}=100-\mathrm{p}, \mathrm{d}$-relative precision of $20 \%$. The calculated sample size was 130 .

\section{Inclusion criteria}

All patients above 18years of age with a psychiatric diagnosis as per the International Classification of Diseases 10 (ICD-10) and receiving at least one psychotropic medication (any medication capable of affecting the mind, emotions, and behavior) for $>1$ month were included in the study. ${ }^{14}$

\section{Exclusion criteria}

Patients who were critically ill or diagnosed as mental retardation or dementia and patients from whom the reliable history of illness cannot be obtained were excluded.

The study was conducted only after obtaining voluntary consent either from the patient or first-degree relatives of the patient. ${ }^{15}$ The tools used for data collection are as follows:

\section{Drug attitude inventory classification $(D A I-10)^{15}$}

Patients' subjective responses and their attitudes towards the treatment were assessed using the validated Spanish version of the drug attitude inventory; a 10-item self-report scale. It was developed to assess patient's belief about the efficacy of drugs which represent subjective experience presented as self-report statements, with which the patient agrees or disagrees. These are based on actual response of patients based on options are true/false only. Each response is scored as +1 if correct or -1 if incorrect. The final score is the grand total of the positive and negative points and ranges in value from -10 to 10 , with higher scores indicating a more positive attitude towards medication. A positive total score means a positive subjective response; whereas negative score means a negative subjective response. The study population was grouped according to their DAI-10 total score. Those who had total scores of more than 0 were classified as "pharmacophilic" 15

\section{Medication adherence rating scale $(M A R S)^{8}$}

The patients were grouped into adherent and nonadherent categories based on the scores obtained from medication adherence rating scale (MARS), which is a ten-item questionnaire, that assigns a score of +1 (positive view of medication usage) and 0 (negative view of medication), allowing total scores ranging between 0 and 10 . Scores are classified as adherent ranging from 6 to 10 , and nonadherent ranging from 0 to 5.8 


\section{Quality of life enjoyment and satisfaction Questionnaire- Short Form $(Q-L E S-Q-S F)^{16}$}

It is a self-reported questionnaire, with 16 items, derived from the general activities scale of the original 93-item form. It evaluates overall enjoyment and satisfaction with physical health, mood, work, household and leisure activities, social and family relationships, daily functioning, sexual life, economic status, overall wellbeing and medications. Responses are scored on a 5-point scale ('not at all or never' to 'frequently or all the time'), where higher scores indicate better enjoyment and satisfaction with life (possible range 14-70). Fourteen summated items create the total Q-LES-Q - SF score. Two last items, about medications and overall quality of life satisfaction, are considered independently. ${ }^{16}$

\section{Statistical analysis}

The statistical analysis of data entry was done using SPSS software version 24.0. Description of categorical variables like gender, socio-economic status etc were mentioned in percentages (\%) and the difference between these variables was analyzed using the Chi-square test. Data related to continuous variables were described in terms of mean and standard deviation (SD) and the difference between these variables were analyzed using Student's ttest and two-tailed with statistical significance of $\mathrm{p}$ $<0.05 .8,15$

\section{RESULTS}

Totally 130 patients were included in the study, among which 116 patients were pharmacophilic and 14 patients were pharmacophobic based on the scores obtained from the DAI scale. Patients who scored $>0$ in the DAI scale were included in the study. The socio-demographic details of the study population are shown in Table 1 . The sociodemographic characteristics does not show any significant variation between groups.

Table 1: Comparison of socio-demographic parameters of patients with pharmacophilia and pharmacophobia with psychiatric disorders.

\begin{tabular}{|c|c|c|c|c|}
\hline Parameter & Total $(n=130)$ & $\begin{array}{l}\text { Patients with } \\
\text { Pharmacophilia }(n=116)\end{array}$ & $\begin{array}{l}\text { Patients with } \\
\text { Pharmacophobia }(n=14)\end{array}$ & P* value \\
\hline \multicolumn{5}{|l|}{ Age (years), n (\%) } \\
\hline $18-29$ & $26(20.0)$ & $23(19.8)$ & $3(21.4)$ & \multirow{5}{*}{0.59} \\
\hline $30-39$ & $32(24.6)$ & $27(23.3)$ & $5(35.7)$ & \\
\hline $40-49$ & $42(32.3)$ & $40(34.5)$ & $2(14.3)$ & \\
\hline $50-59$ & $20(15.4)$ & $17(14.7)$ & $3(21.4)$ & \\
\hline$\geq 60$ & $10(1.7)$ & $9(7.8)$ & $1(7.1)$ & \\
\hline \multicolumn{5}{|l|}{ Gender, n (\%) } \\
\hline Male & $78(60.0)$ & $69(59.5)$ & $9(64.3)$ & \multirow{2}{*}{0.73} \\
\hline Female & $52(40.0)$ & $47(40.5)$ & $5(35.7)$ & \\
\hline \multicolumn{5}{|c|}{ Socio-economic status, n (\%) } \\
\hline Poor class & $1(61.2)$ & $17(14.7)$ & $4(28.6)$ & \multirow{4}{*}{0.33} \\
\hline Middle class & $89(69.5)$ & $80(69.0)$ & $9(64.3)$ & \\
\hline Upper middle class & $20(15.4)$ & $19(16.4)$ & $1(7.1)$ & \\
\hline High class & 0 & 0 & 0 & \\
\hline \multicolumn{5}{|l|}{ Education, n (\%) } \\
\hline Illiterate & $22(16.9)$ & $18(15.5)$ & $4(28.6)$ & \multirow{5}{*}{0.34} \\
\hline Primary & $48(36.9)$ & $43(37.1)$ & $5(35.7)$ & \\
\hline Secondary & $34(26.2)$ & $33(28.4)$ & $1(7.1)$ & \\
\hline Graduate & $24(18.5)$ & $20(17.2)$ & $4(28.6)$ & \\
\hline Post-graduate & $2(1.5)$ & $2(1.7)$ & 0 & \\
\hline \multicolumn{5}{|c|}{ Marital status, n (\%) } \\
\hline Single & $31(23.8)$ & $27(22.4)$ & $4(35.7)$ & \multirow{2}{*}{0.49} \\
\hline Married & $99(76.2)$ & $90(77.6)$ & $9(64.3)$ & \\
\hline \multicolumn{5}{|c|}{ Family history, n (\%) } \\
\hline Present & $32(24.6)$ & $31(26.7)$ & $1(7.1)$ & \multirow{2}{*}{0.32} \\
\hline Absent & $98(75.4)$ & $85(73.3)$ & $13(92.9)$ & \\
\hline \multicolumn{5}{|l|}{ Occupation, n (\%) } \\
\hline Employed & $79(60.8)$ & $72(62.1)$ & $7(50)$ & \multirow{2}{*}{0.38} \\
\hline Unemployed & $51(39.2)$ & $44(37.9)$ & $7(50)$ & \\
\hline
\end{tabular}

Values are expressed as frequency and percentage (n, \%). Comparison of pharmacophilic and pharmacophobic was done using chi-square test. *p value $<0.05$ was considered statistically significant. 
Table 2: Comparison of clinical characteristics of patients with pharmacophilia and pharmacophobia patients.

\begin{tabular}{|c|c|c|c|c|}
\hline Parameter & Total(n=130) & $\begin{array}{l}\text { Patients with } \\
\text { Pharmacophilia }(n=116)\end{array}$ & $\begin{array}{l}\text { Patients with } \\
\text { Pharmacophobia }(n=14)\end{array}$ & $\begin{array}{l}\mathbf{P} * \\
\text { Value }\end{array}$ \\
\hline \multicolumn{5}{|l|}{ Diagnosis, n (\%) } \\
\hline Anxiety & $13(10.0)$ & $11(9.5)$ & $2(14.3)$ & \multirow{7}{*}{0.74} \\
\hline Depression & $28(21.5)$ & $26(22.4)$ & $2(14.3)$ & \\
\hline Mania & $9(6.9)$ & $9(7.8)$ & 0 & \\
\hline BPAD & $12(9.2)$ & $11(9.5)$ & $1(7.1)$ & \\
\hline Schizophrenia & $20(15.4)$ & $17(14.7)$ & $3(21.4)$ & \\
\hline ADS & $17(13.1)$ & $16(13.8)$ & $1(7.1)$ & \\
\hline Others & $31(23.8)$ & $26(22.4)$ & $5(35.7)$ & \\
\hline \multicolumn{5}{|c|}{ Co morbid conditions, n (\%) } \\
\hline Diabetes mellitus & $18(13.8)$ & $17(14.7)$ & $1(7.1)$ & \multirow{5}{*}{0.74} \\
\hline Hypertension & $15(11.5)$ & $14(12.1)$ & $1(7.1)$ & \\
\hline Thyroid disorders & $4(3.1)$ & $4(3.4)$ & 0 & \\
\hline Others & $2(1.5)$ & $2(1.7)$ & 0 & \\
\hline NIL & $91(70)$ & $79(68.1)$ & $12(85.7)$ & \\
\hline \multicolumn{5}{|l|}{ Drugs, n (\%) } \\
\hline Anti-anxiety & $27(20.8)$ & $27(23.3)$ & 0 & $0.04 *$ \\
\hline Anti-psychotics & $79(60.8)$ & $68(58.6)$ & $11(78.6)$ & 0.34 \\
\hline Anti-depressants & $53(40.8)$ & $48(41.4)$ & $5(35.7)$ & 0.68 \\
\hline Anti-manic & $13(10.0)$ & $10(8.6)$ & $3(21.4)$ & 0.13 \\
\hline Sedative-hypnotics & $43(33.1)$ & $35(30.2)$ & $8(57.1)$ & $0.04 *$ \\
\hline Anti-epileptics & $57(43.8)$ & $51(44.0)$ & $6(42.9)$ & 0.9 \\
\hline Anti-parkinsonism & $33(25.4)$ & $26(22.4)$ & $7(50.0)$ & $0.02 *$ \\
\hline Others & $52(40.0)$ & $45(38.8)$ & $7(50.0)$ & 0.9 \\
\hline
\end{tabular}

Values are expressed as frequency $(\mathrm{n} \%)$ percentage and comparison of pharmacophilic and pharmacophobic was done using chi-square test. *p value $<0.05$ was considered statistically significant.

Table 3: Comparison of medication adherence among pharmacophilic and pharmacophobic groups of patients.

\begin{tabular}{|c|c|c|c|c|}
\hline & $\begin{array}{l}\text { Total patients } \\
(\mathrm{n}=130)\end{array}$ & $\begin{array}{l}\text { Pharmacophilic } \\
\text { Patients }(\mathbf{n}=\mathbf{1 1 6})\end{array}$ & $\begin{array}{l}\text { Pharmacophobic } \\
\text { Patients }(n=24)\end{array}$ & P* value \\
\hline Medication Adherence n (\%) & $97(74.6)$ & $95(81.9)$ & $2(14.3)$ & \multirow{2}{*}{$0.00 *$} \\
\hline Medication Non-Adherence n (\%) & $33(25.4)$ & $21(18.1)$ & $12(85.7)$ & \\
\hline
\end{tabular}

*p value of $<0.05$ was considered statistically significant. Here medication adherence is expressed as (n, \%) percentages for both group of patients and was compared using chi-square test.

Clinical characteristics of the patients such as diagnosis, co-morbidities, and common class of drugs prescribed are interpreted in Table 2. In this study, clinical diagnosis of depression, schizophrenia, alcohol dependent syndrome (ADS) were more in pharmacophilic patients than pharmacophobic patients but there was no significant difference observed statistically. Antipsychotics, antidepressants, anti-epileptics group of drugs were most commonly prescribed in pharmacophilic group, than pharmacophobic groups of patients. But there was no statistical significance with drugs and co-morbidities among both groups of patients.

Among 114 pharmacophilic patients, 95 patients (81.9\%) showed adherence to the prescribed medications while 21 patients $(18.1 \%)$ were non-adherent, with regard to 14 pharmacophobic patients, only $2(14.3 \%)$ patients showed adherence towards medication and remaining $12(85.7 \%)$ were nonadherent according to analysis done by using MARS questionnaire. The adherence score was found to be significantly higher among patients with pharmacophilia than pharmacophobia (Table 3).

Quality of life index for both groups was assessed using QLES-Q-SF scale. The mean score of the individual item in Q-LES-Q-SF was compared between both groups. The results showed better quality of life index in pharmacophilic than pharmacophobic patients $(p<0.05)$ with statistical significance of $p<0.05$ as shown in Table 4 . The mean overall score of phamacophilic patients (63.59 \pm 11.6$)$ was higher compared (using student's t-test and results were two-tailed) with that of pharmacophobic $(52 \pm 14.8)$ with significant $\mathrm{p}$ value of $\mathrm{p}=0.002$ (Table 5). 
Table 4: Comparison of quality of life enjoyment and satisfaction questionnaire - short form (Q-LES-Q-SF) among pharmacophilic and pharmacophobic patients.

\begin{tabular}{|llll|}
\hline Variables & $\begin{array}{l}\text { Pharmacophilic } \\
(\mathbf{n = 1 1 6})\end{array}$ & $\begin{array}{l}\text { Pharmacophobic } \\
(\mathbf{n = 1 4})\end{array}$ & \begin{tabular}{l} 
P value \\
\hline Physical health
\end{tabular} \\
$3.66 \pm 0.697$ & $2.714 \pm 0.914$ & $0.000^{*}$ \\
\hline Mood & $3.80 \pm 0.688$ & $2.57 \pm 0.938$ & $0.000^{*}$ \\
\hline Work & $3.67 \pm 0.670$ & $2.71 \pm 1.13$ & $0.000^{*}$ \\
\hline Household activities & $3.61 \pm 0.707$ & $2.71 \pm 0.994$ & $0.000^{*}$ \\
\hline Social relationships & $3.48 \pm 0.639$ & $2.93 \pm 0.730$ & $0.016^{*}$ \\
\hline Family relationships & $3.47 \pm 0.691$ & $3.21 \pm 0.893$ & 0.201 \\
\hline Leisure time activities & $3.33 \pm 0.629$ & $3.00 \pm 0.555$ & $0.055^{*}$ \\
\hline Ability to function in daily life & $3.28 \pm 0.630$ & $2.928 \pm 0.475$ & $0.020^{*}$ \\
\hline Sexual drive, interest and/or performance & $3.16 \pm 0.574$ & $3.00 \pm 0.392$ & 0.302 \\
\hline Economic status & $3.28 \pm 0.584$ & $3.00 \pm 0.961$ & 0.126 \\
\hline Living/housing situation & $3.34 \pm 0.661$ & $3.00 \pm 0.877$ & 0.078 \\
\hline $\begin{array}{l}\text { Ability to get around physically without feeling dizzy or } \\
\text { unsteady or falling }\end{array}$ & $3.61 \pm 0.743$ & $3.07 \pm 0.977$ & $0.015^{*}$ \\
\hline Your vision in terms of ability to do work or hobbies & $3.65 \pm 0.749$ & $3.00 \pm 0.877$ & $0.003^{*}$ \\
\hline Overall sense of well being & $3.79 \pm 0.666$ & $3.00 \pm 0.961$ & $0.000^{*}$ \\
\hline
\end{tabular}

Table 5: Comparison of overall percentile of quality of life enjoyment and satisfaction questionnaire-short form (Q-LES-Q-SF) among pharmacophilic and pharmacophobic patients.

\begin{tabular}{|lll|l|}
\hline $\begin{array}{l}\text { Mean } \\
(\%) \pm S D\end{array}$ & $\begin{array}{l}\text { Pharmacophil } \\
\text { ic }(\mathrm{n}=116)\end{array}$ & $\begin{array}{l}\text { Pharmacophob } \\
\text { ic }(\mathbf{n}=14)\end{array}$ & $\begin{array}{l}\mathbf{P} \\
\text { value }\end{array}$ \\
\hline $\begin{array}{l}\text { Total } \\
\text { Percentile }\end{array}$ & $63.59 \pm 11.605$ & $52.86 \pm 14.06$ & $0.002^{*}$ \\
\hline
\end{tabular}

Comparison of overall percentages of both groups of patients were expressed as (mean $\pm \mathrm{SD}$ ) done using student's t-test and values were two-tailed. *p value of 0.002 was considered to be statistically significant.

\section{DISCUSSION}

Previous Studies had revealed that patient's attitude towards medication has an important role in medication adherence. ${ }^{15-18}$ It has been reported that nonadherence is the common factor among psychiatric patients. ${ }^{15}$ The current study was emphasized on factors influencing pharmacophilic and pharmacophobic attitude and their impact over medication adherence and improvement in their quality of life. But in present study, there was no statistical difference observed in pharmacophilic and pharmacophobic group of patients, in relation to sociodemographic details like age, gender, marital status, education and family history which conveys that, these details do not have any significant role among pharmacophilic and pharmacophobic attitude among psychiatric patients. Present study clearly implies that there was no correlation between education level and patients' attitude towards medication, which is compatible with the previous finding of Christudas et al, whereas a study in Spain has shown that patients attitude towards medication re-laid on the educational level of the patient. ${ }^{6,15}$
In present study, most of the patients were diagnosed to have depression, schizophrenia, and ADS in the pharmacophilic group compared to pharmacophobic group which contradicts with the study results conducted in Karnataka and Spain. ${ }^{14,19}$ Medication history of patients with pharmacophobia reveals that, the most common psychotropic agents used were antipsychotics, which was consistent with the previous studies. ${ }^{15,20,21}$ Whereas antidepressants, anti-epileptics, antipsychotics were found to be used in higher number of patients in pharmacophilic group, which is consistent with results of Husain et al. ${ }^{15,22}$

In this study, patients with pharmacophilia were found to have statistically significant higher adherence score towards medications compared, to that of pharmacophobia with lower adherence towards prescribed medications which correlates with the previous finding. ${ }^{15}$ The results of this study confirm that pharmacophilia or pharmacophobia toward psychopharmacological agents can significantly have impact over medication adherence of the psychiatric patients, thereby proving proposed hypothesis. This study has also confirmed that DAI-10 and MARS scores had a significant relationship towards medication which shows patients adherence.

Medication adherence has a role in improving the quality of life among psychiatric patients. So, this study was designed to analyse the quality of life improvement among both groups. In this study, authors used QOL-Q-SF scale since it has shown good stability, reliability, validity among non-psychiatric people and in patients with a range of psychiatric illnesses like mood disorders, schizophrenia and anxiety disorders with the previous studies and also it is said to have $80 \%$ sensitive and $100 \%$ specific measure. ${ }^{23}$ This short form (Q-LES-Q-SF) was most frequently used 
for analysis of treatment outcome results among the psychiatry research.

Quality of life enjoyment and satisfaction questionnaireshort form scores maximum of 70 and a minimum of 14 . The items of this scale were internally consistent enough to assess the quality of life among psychiatric patients. Validation of the scale in assessing these important factors is an initial step in understanding the full impact of our treatments for psychiatric disorders to improve their quality of life. ${ }^{24}$ Q-LES-Q-SF total score and percentile response in patients with pharmacophilia (64\%) and pharmacophobia (53\%) were observed. Severity of pharmacophobia was associated with decreasing quality of life compared to that of pharmacophilic group. The individual variables in both groups of patients were compared and there was statistically significant differences with reference to physical health, mood, work, household activities, social relationships, ability to function in routine life, living or housing situation, ability to get around without feeling dizzy or falling, vision in terms of ability, to do work or hobbies, overall sense of well-being, medication, overall life satisfaction in pharamacophilic compared to pharmacophobic group. There was no significant change observed with family relationships, leisure time activities, sexual drive, interest and/or performance, economic status, in our research which contradicts the findings of previous study Demyttenere et al. ${ }^{25}$

In pharmacophobic patients, medication nonadherence might be due to feeling of the recovery or cure from the disease, or by thoughts of spiritual beliefs for their cause of illness, awareness about side effects of prescribed medications through various medias and long stay in hospitals and continuous intake of drugs for the lifetime. ${ }^{8}$ From the above findings, it is clear that there are large number of factors contributing to medication nonadherence, so the strategy needs to be improvised not only for proper medications but also proper counselling of patients by psychiatrists, psychologists, family members and relative's social support to the patients for better therapeutic outcome from psychiatric illnesses.

\section{CONCLUSION}

This study concludes that the pharmacophilic group has higher adherence towards prescribed medications and had good quality of life index compared to that of the pharmacophobic group. But the nonadherence in the pharmacophobic group patients might be due to the feeling of recovery or cure from disease and discontinuing the treatment, on their own accord. The superstitious beliefs and traditional follow-up of medicines, or fear of sideeffects of prescribed medications by the doctors may also have an association for lower adherence of pharmacophobic group. However, nonadherence among psychiatric illnesses would increase the risk of morbidity and mortality among the psychiatric population, which has to be considered and taken care off by health care providers. So, proper counselling of pharmacophobic patients by psychiatrists or psychologists might improve medication adherence and also helps in improving the QOL among patients with psychiatric illness.

\section{ACKNOWLEDGEMENTS}

Authors would like to thank authorities of Sri Manakula Vinayagar Medical College and Hospital. Authors also acknowledge Department of Psychiatry helping in conducting this study and Department of Community Medicine for their technical support.

\section{Funding: No funding sources \\ Conflict of interest: None declared}

Ethical approval: The study was approved by the Institutional Ethics Committee

\section{REFERENCES}

1. Venkatashiva BR, Gupta A, Lohiya A, Kharya P. Mental health issues and challenges in India: a review. Int J Sci Res Pub. 2013;3(2):1-8.

2. World Health Organization. World mental health surveys find mental disorders are widespread, disabling and often go untreated. 2004. Available at: http://www.who.int/mediacentre/news/notes/2004/np 14/en/.

3. Math SB, Srinivasaraju R. Indian Psychiatric epidemiological studies: Learning from the past. Indian J Psychiatry. 2010 Jan;52(Suppl1):S95.

4. Geyer MA, Olivier B, Joëls M, Kahn RS. From antipsychotic to anti-schizophrenia drugs: role of animal models. Trends Pharmacol Sci. 2012 Oct 1;33(10):515-21.

5. De las Cuevas C. Towards a clarification of terminology in medicine taking behavior: compliance, adherence and concordance are related although different terms with different uses. Curr Clin Pharmacol. 2011 May 1;6(2):74-7.

6. De las Cuevas C, Peñate W. Explaining pharmacophobia and pharmacophilia in psychiatric patients: relationship with treatment adherence. Human Psychopharmacol: Clin Experimental. 2015 Sep;30(5):377-83.

7. De las Cuevas C, Peñate W, Cabrera C. Are acceptance and skepticism determinant factors for adherence to drug treatment in psychiatric patients?. J Clin Psychopharmacol. 2016 Dec 1;36(6):724-5.

8. Chukwujekwu CD, Adesokun OK. Prevalence of medication non-adherence among psychiatric patients in a tertiary hospital in Nigeria. J Biosci Med. 2017;5:1-10.

9. Dimatteo MR, Giordani PJ, Lepper HS, Croghan TW. Patient adherence and medical treatment outcomes a meta-analysis. Medical Care. 2002 Sep 1:794-811.

10. Sabate E. Adherence to long-term therapies: evidence for action. World Health Organization 2003. Available at 
:http://www.who.int/chp/knowledge/publications/adh erence_report/en/.

11. Lacro JP, Dunn LB, Dolder CR, Leckband SG, Jeste DV. Prevalence of and risk factors for medication nonadherence in patients with schizophrenia: a comprehensive review of recent literature. J Clin Psychiatry. 2002;63:892-909.

12. Morken G, Widen JH, Grawe RW. Non-adherence to antipsychotic medication, relapse and rehospitalisation in recent-onset schizophrenia. BMC Psychiatry. 2008 Dec;8(1):32.

13. Rapaport MH, Clary C, Fayyad R, Endicott J. Qualityof-life impairment in depressive and anxiety disorders. Am J Psychiatry. 2005 Jun 1;162(6):1171-8.

14. Sibitz I, Katschnig H, Goessler R, Unger A, Amering M. Pharmacophilia and pharmacophobia: determinants of patients' attitudes towards antipsychotic medication. Pharmacopsychiatry. 2005 May;38(03):107-12.

15. Christudas MJ, Gupta BS, Undela K, Isaac NM, Ram D, Ramesh M. Assessment of impact of pharmacophilia and pharmacophobia on medication adherence in patients with psychiatric disorders: A cross-sectional study. Indian J Pharmacol. 2016 Nov;48(6):701.

16. Endicott J, Nee J, Harrison W, Blumenthal R. Quality of Life Enjoyment and Satisfaction Questionnaire: a new measure. Psychopharmacol Bulletin. 1993.

17. Keith SJ, Kane JM. Partial compliance and patient consequences in schizophrenia: our patients can do better. J Clin Psychiatr. 2003 Nov;64(11):1308-15.

18. Fenton WS, Blyler CR, Heinssen RK. Determinants of medication compliance in schizophrenia: empirical and clinical findings. Schizophrenia Bulletin. 1997 Jan $1 ; 23(4): 637-51$.

19. De las Cuevas C, Marrero R, Cabrera C. Treatmentrelated decisional conflict in patients with depressive and anxious disorders. Patient Preference Adherence. 2016;10:1011-9.
20. Hofer A, Kemmler G, Eder U, Honeder M, Hummer M, Fleischhacker WW. Attitudes toward antipsychotics among outpatient clinic attendees with schizophrenia. J Clin Psychiatry. 2002 Jan;63(1):4953.

21. Lauber C, Nordt C, Falcato L, Rössler W. Lay recommendations on how to treat mental disorders. Social Psychiatry Psychiatric Epidemiol. 2001 Nov 1;36(11):553-6.

22. Husain T, Ahmed HF, Maboos M, Gul S. Pharmacophilia: Prevalence and trends in our community. World J Pharm Sci. 2014;2:346-9.

23. Ritsner M, Kurs R, Gibel A, Ratner Y, Endicott J. Validity of an abbreviated quality of life enjoyment and satisfaction questionnaire (Q-LES-Q-18) for schizophrenia, schizoaffective, and mood disorder patients. Quality Life Res. 2005 Sep 1;14(7):1693703.

24. Mick E, Faraone SV, Spencer T, Zhang HF, Biederman J. Assessing the validity of the quality of life enjoyment and satisfaction questionnaire-short form in adults with ADHD. J Attention Disorders. 2008 Jan;11(4):504-9.

25. Demyttenaere K, Andersen HF, Reines EH. Impact of escitalopram treatment on Quality of Life Enjoyment and Satisfaction Questionnaire scores in major depressive disorder and generalized anxiety disorder. Int Clin Psychopharmacol. 2008 Sep 1;23(5):276-86.

Cite this article as: Ganesan S, Selvaraj N, Dass VK, Jayabalan N, Rajamohammad MA, Anandan I. A. Assessment of drug attitude, medication adherence and quality of life among psychiatric patients in South Indian population: a cross sectional study. Int J Basic Clin Pharmacol 2019;8:61-7. 